\title{
Electrical Coupling Synchronizes Subthreshold Activity in Locus Coeruleus Neurons in vitro from Neonatal Rats
}

\author{
M. J. Christie, J. T. Williams, and R. A. North \\ Vollum Institute, Oregon Health Sciences University, Portland, Oregon 97201
}

\begin{abstract}
Locus coeruleus neurons in brain slices prepared from neonatal rats have rhythmic oscillations in membrane potential at frequencies ranging from 0.3 to $3 \mathrm{~Hz}$. Recordings from pairs of neurons separated by $50-300 \mu \mathrm{m}$ showed that this oscillatory activity was synchronized at ages less than $24 \mathrm{~d}$. Slices cut from rats 24-27 d old showed rhythmic activity which was only partially synchronous between cell pairs, but full synchrony could be restored by superfusion with tetraethylammonium $(2 \mathrm{mM})$ and/or barium $(2 \mathrm{mM})$. No synchronous rhythmic activity was observed between neurons in slices from rats $\mathbf{4 0} \mathrm{d}$ old, even in the presence of tetraethylammonium and barium. In those cells in which rhythmic potential oscillations were synchronous, action potentials occurring in one cell were not observed in the second cell. Electrotonic coupling was directly demonstrated between $41 \%$ of neurons ( 12 of 29 pairs) in slices from rats $<10 \mathrm{~d}$ old but not in tissue from older rats (4 pairs). The input resistance of neurons from neonatal rats $(<15 \mathrm{~d}$ old $)$ was about half $(81 \mathrm{M} \Omega)$ that measured under identical conditions from neurons from adult rats $(213 \mathrm{M \Omega})$. The electrotonic potential in cells from rats $<\mathbf{1 5} \mathrm{d}$ old was best fit by a double exponential, whereas that from adults was best fit by a single exponential. The results demonstrate that significant electrical coupling occurs among locus coeruleus neurons from neonatal rats; this appears to decline with age. The coupling serves as a low-pass filter and causes the synchronized occurrence of membrane potential oscillations. Such a rhythmic background activity within the entire nucleus may be important for the widespread trophic role of the noradrenergic neurons during development.
\end{abstract}

The locus coeruleus (LC) has been widely postulated to play an important role in CNS development because its early differentiation and innervation of target areas often precedes cytogenesis, cell migration, and innervation by other afferent systems (Lauder and Bloom, 1974). LC neurons undergo their final division and contain catecholamine synthetic enzymes 9-12 d prior to birth [gestational days 10-13 (E10-E13); Lauder and Bloom 1974; Specht et al., 1981], being the first of the monoaminergic cell groups to differentiate. Innervation of the neocortex, as revealed by dopamine hydroxylase histochemistry, is detectable by E16, and LC neurons can be antidromically ac-

Received Nov. 11, 1988; revised Mar. 13, 1989; accepted Apr. 11, 1989.

Supported by grants DA04523 and DA03161. We thank Dr. Craig Jahr for suggestions on the manuscript.

Correspondence should be addressed to Dr. Christie at the above address.

Copyright $\odot 1989$ Society for Neuroscience $0270-6474 / 89 / 103584-06 \$ 02.00 / 0$ tivated from frontal cortex as early as E18 (Sakaguchi and Nakamura, 1987). In neonatal rats (Pl-P6) catecholamine-containing terminals arising from LC contribute up to $70 \%$ of synapses in discrete laminae of somatosensory cortex, whereas the proportion is about $1 \%$ in the adult (Coyle and Molliver, 1977). Experimental manipulations of neonatal LC projections using neurotoxins also suggest a possible trophic role in development (Felten et al., 1982).

Knowledge of the physiological properties of the neonatal LC itself might be crucial to an understanding of its role in development. Extracellular recordings from neonatal (P1-P3) and fetal (E18-E22) LC neurons in anesthetized rats (Kimura and Nakamura, 1985; Sakaguchi and Nakamura, 1987) revealed that the majority of neurons were not spontaneously active but displayed sporadic discharge that was synchronous throughout many or all LC neurons. Although synaptogenesis in the LC commenced around E1 8-E19 and was sparse until the fifth postnatal day (Lauder and Bloom, 1975), LC discharge was strongly activated by non-noxious sensory stimuli. These studies contrast with findings in anesthetized adult rats, in which most LC neurons display low rates of spontaneous discharge $(1-4 \mathrm{~Hz})$ and are activated by noxious but not non-noxious stimuli (Foote et al., 1983).

LC neurons in brain slices kept in vitro also displayed different properties between neonate and adult (Williams and Marshall, 1987). The majority of neurons was spontaneously active in both neonates and adults; however, in the neonates the action potentials arose from the peaks of rhythmic oscillations in membrane potential $(0.5-3 \mathrm{~Hz}, 2-20 \mathrm{mV})$. These rhythmic potentials were dependent on extracellular calcium and resistant to tetrodotoxin (TTX). The finding that they were unaffected by imposed changes in membrane potential suggested that they probably were generated at sites some distance from the intracellular recording electrode.

A possible explanation of these findings is that the neurons are extensively coupled by low-resistance pathways, as occurs in several other central nuclei early in development (e.g., Connors et al., 1983). In the present experiments, simultaneous intracellular recordings were made from pairs of LC neurons in a test of this hypothesis. A preliminary report of these results has been published (Christie et al., 1987).

\section{Materials and Methods}

Intracellular recordings were made from LC neurons from neonatal rats using techniques previously described for adult rats (Williams et al., 1984). Briefly, rats of either sex were used, in the age range $1-40 \mathrm{~d}$. These animals were anesthetized with halothane and killed by decapitation. In most experiments, coronal sections of pons ( $400 \mu \mathrm{m}$ thick) were prepared using a vibratome and completely submerged in a heated $\left(37^{\circ} \mathrm{C}\right)$, flowing $(1.5 \mathrm{ml} / \mathrm{min})$ physiological saline of the following com- 


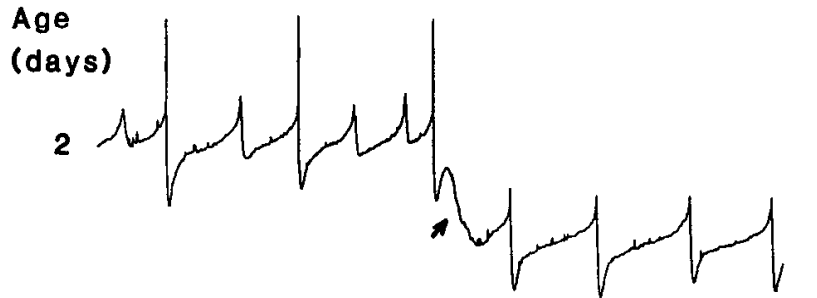

$9 N M M M N M N M N M N M N$
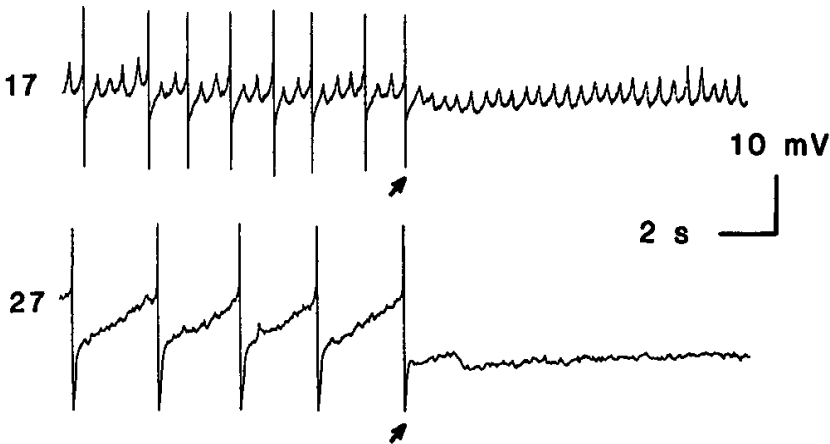

Figure 1. Representative intracellular recordings of spontaneous activity of $L C$ neurons at various ages. Action potentials (threshold about $-55 \mathrm{mV}$ ) usually arose from the peak depolarizing phase of rhythmic potential variations. Full action potential amplitude is not shown (limited by frequency response of chart recorder). The membrane was hyperpolarized at arrow by passing current $(50-200 \mathrm{pA})$ through the recording electrode. The amplitude of rhythmic potential variations declined and their frequency increased with age, becoming undetectable by $27 \mathrm{~d}$. position (mM): $\mathrm{NaCl}, 126 ; \mathrm{KCl}, 2.5 ; \mathrm{CaCl}_{2}, 2.5 ; \mathrm{MgCl}_{2} 1.2 ; \mathrm{NaH}_{2} \mathrm{PO}_{4}$, 1.2; $\mathrm{NaHCO}_{3} 25 ;$ glucose, 11 ; this was gassed with $95 \% \mathrm{O}_{2} / 5 \% \mathrm{CO}_{2}$. In animals less than 7-8 d old, the LC was identified visually in the slice of pons as a translucent, crescent-shaped cellular region bordered by the fourth ventricle. In older animals, myelination of the mesencephalic tract of the trigeminal nerve also helped to identify the nucleus. Intracellular recordings were made with microelectrodes (30-70 M $\Omega$, filled with $2 \mathrm{M} \mathrm{KCl}$ ). Recordings of membrane potential from each neuron were plotted simultaneously on a chart recorder. In some experiments, evoked membrane potential changes were averaged and plotted on an $x / y$ recorder. Electrotonic potentials were digitized at intervals of 0.1 $\mathrm{msec}$ and fitted to one or more exponential functions by a least-squares minimizing method (Statistical Graphics Corporation). The correlation coefficients for the fits to 1 or 2 exponentials were tested to determine whether they were significantly different $(p<0.05)$ before concluding that the electrotonic potential was better fit by 1 or 2 exponentials. The results of this test conformed well to the impression from visual inspection of the electrotonic potentials. All data are presented as means $\pm \mathrm{SE}$.

\section{Results}

The membrane properties of $\mathrm{LC}$ neurons from neonates were essentially the same as previously described (Williams and Marshall, 1987). Cells fired spontaneous action potentials as frequencies ranging from 0.2 to $4 \mathrm{~Hz}$, even in sliccs from the youngest animals (Fig. 1). In the absence of any applied currents, action potentials $65-80 \mathrm{mV}$ in amplitude and $1.2-2.7 \mathrm{msec}$ in duration arose from a threshold of about $-55 \mathrm{mV}$ and were followed by afterhyperpolarizations of $10-20 \mathrm{mV}$ amplitude and 100-300 msec duration. The main difference between the neonatal cells and the adult cells was that the action potentials arose from the peak of the depolarizing phase of slow, rhythmic oscillations in membrane potential (Fig. 1). In slices from animals $<21$ d old, $96 \%$ of neurons (110/114) displayed slow rhythmic oscillations. These often took 10-15 min to develop and become stable after the intracellular penetration; they were not seen with the electrode tip in an immediately extracellular position. The

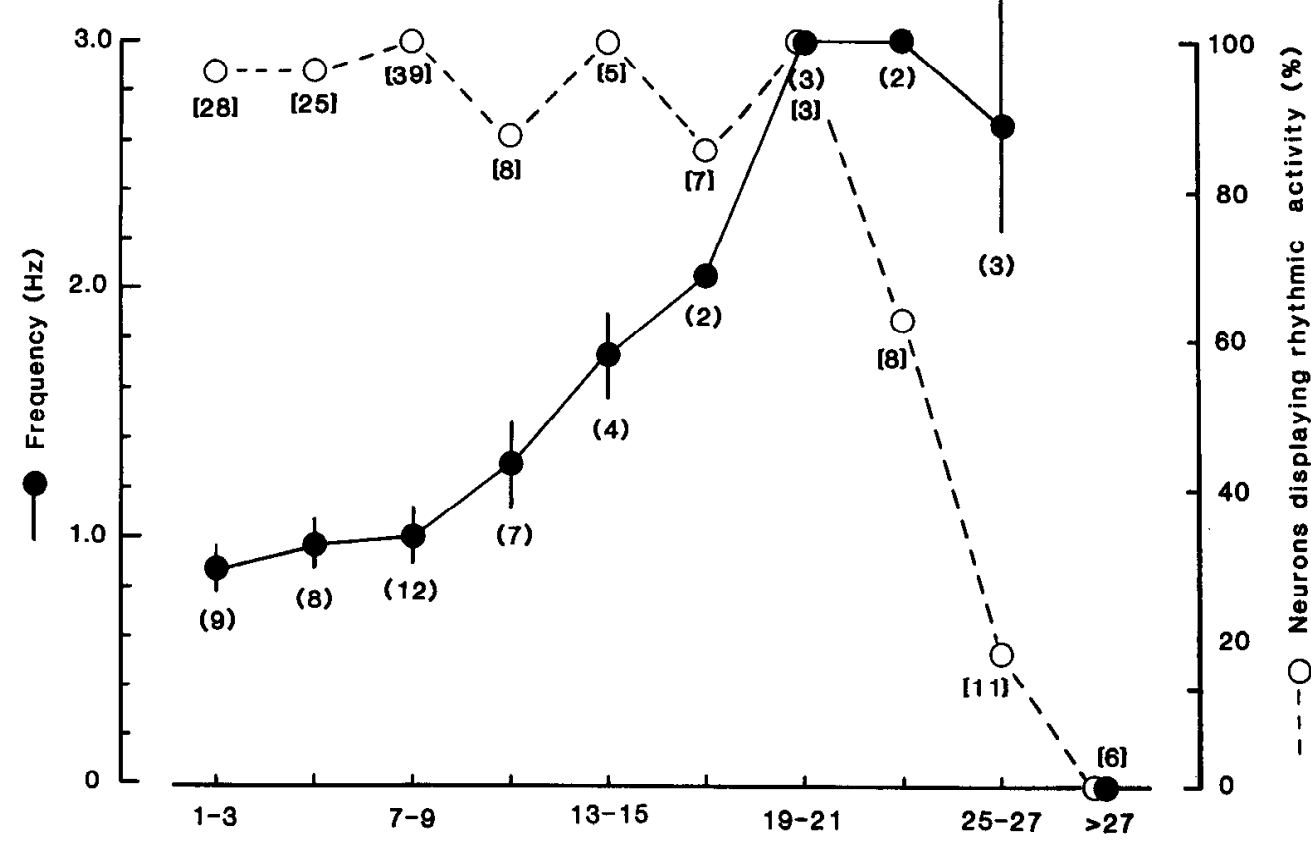

Age (days)
Figure 2. Proportion of neurons displaying rhythmic potential variations (and their frequency) as a function of age. Filled circles, left ordinate: frequency of rhythmic potentials (mean \pm $\mathrm{SE}$, number of cells indicated by each point). Open circles, right ordinate: proportions of neurons at each age which displayed rhythmic potential variations (total number of neurons indicated by each point). 


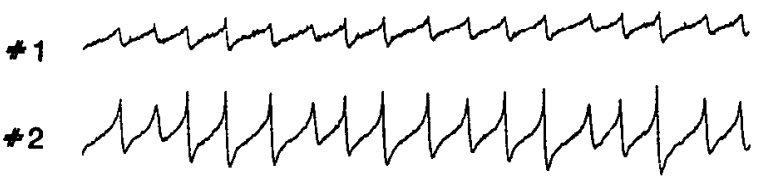

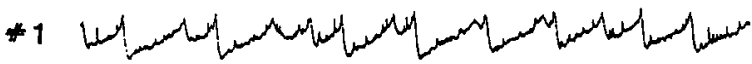

$* 3$

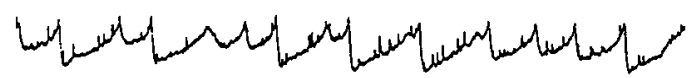

$+1$

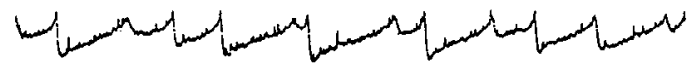

*4

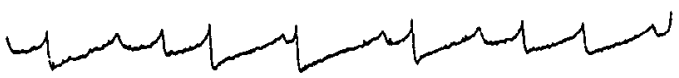

$+1$

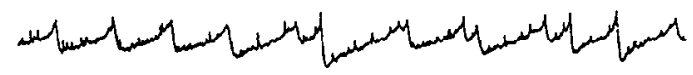

45

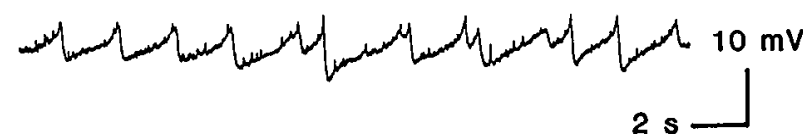

Figure 3. Rhythmic potentials are fully synchronous between all neurons in the LC from a 3-d-old rat. Each pair of records are simultaneous recordings of membrane potential from 2 neurons. Impalement of neuron 1 was maintained for $3 \mathrm{hr}$. Neurons $2-5$ were sequentially impaled with a second electrode in the ipsilateral LC. Recording electrodes were separated by about $100-300 \mu \mathrm{m}$. Spontaneous action potentials were prevented by passing current (50-150 pA) through the recording electrode.

proportion of cells showing rhythmic oscillations of potential declined in older rats, and oscillations were rarely observed in slices from animals older than $27 \mathrm{~d}$ (Fig. 2).

\section{Synchronous activity}

The rhythmic oscillations in membrane potential were synchronous through the LC of neonatal rats. In Figure 3 recordings from 5 LC neurons are shown; one neuron (\#1) was impaled throughout, and 4 other neurons were impaled consecutively with a second electrode. They were located up to $300 \mu \mathrm{m}$ distant from the first neuron. Oscillatory potentials in these 4 neurons were synchronous with those in the first neuron (within the limit of resolution imposed by the frequency response of the pen recorder, about $30 \mathrm{msec}$ ). Full action potentials, which always occurred at the peak of the slow depolarization, were not synchronized in any pairs. Similar observations were made during simultaneous recordings from 48 pairs of LC neurons from animals $<24 \mathrm{~d}$ old. In slices from rats aged between 24 and $27 \mathrm{~d}$ ( 8 pairs), rhythmic activity was either absent or only partially synchronous (Fig. 4). In these cases, tetraethylammonium (TEA, $20 \mathrm{~mm})$ and/or $\mathrm{BaCl}_{2}(2 \mathrm{~mm})$ increased the amplitude of the slow oscillations, as well as causing synchrony of oscillations already present (Fig. 4B).

Simultaneous recordings from 3 pairs of neurons in the right and left LC in the same slice revealed no synchronous activity. Synchrony of rhythmic activity was not dependent on the plane
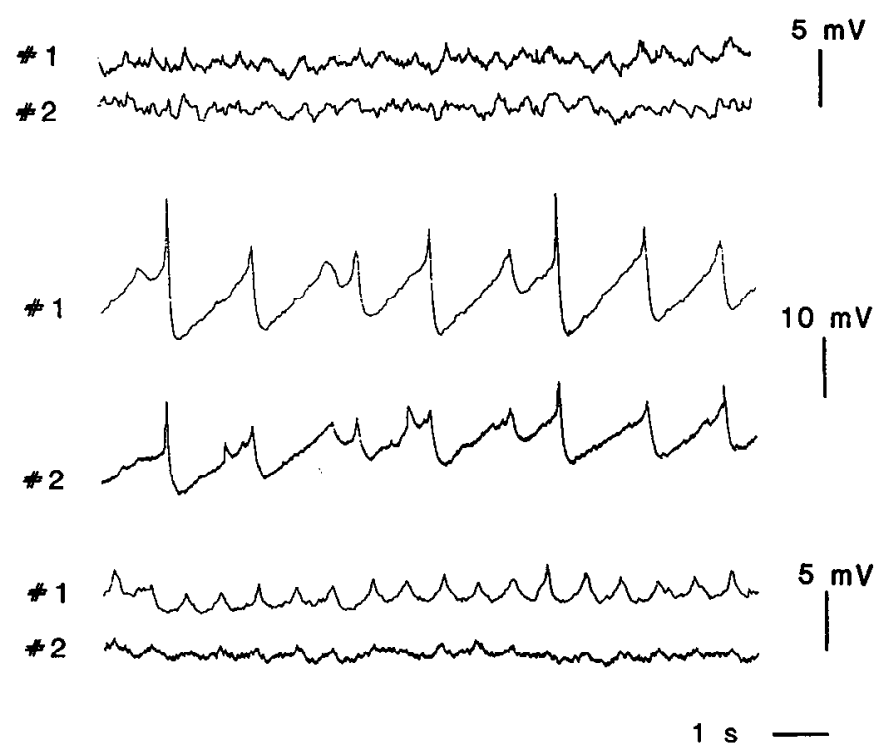

Figure 4. Simultaneous recordings from LC neurons from a 24-d-old rat (electrode separation about $100 \mu \mathrm{m}$ ). Top 2 traces show control recordings. Middle 2 traces show partial synchrony of rhythmic potentials during superfusing with $10 \mathrm{~mm}$ tetraethylammonium and $2 \mathrm{~mm}$ barium. Asynchronous activity returned after $20 \mathrm{~min}$ washout (bottom 2 traces). Spontaneous action potentials were prevented by passing current through the recording electrodes.

of section through dendritic arborizations. LC dendrites are largely radial in the sagittal plane (Groves and Wilson, 1980). In 3 parasagittal slices prepared from 6-to 8-d-old rats, 7 pairs of neurons displayed synchronous rhythmic oscillations with a frequency of $1.1 \pm 0.1 \mathrm{~Hz}$.

TTX $(1 \mu \mathrm{M})$ always reversibly blocked the regenerative, fastrising sodium action potentials (see Williams et al., 1984) but had no effect on rhythmic oscillations in 3 of 5 cells. In 2 cells the rhythmic oscillations were prevented when TTX was added but could be restored by the addition of TEA $(10 \mathrm{mM})$ or $\mathrm{BaCl}_{2}$ ( $2 \mathrm{mM}$ ) to the TTX-containing solution. TTX did not affect the synchrony between pairs.

\section{Input resistance and time constant}

Electrotonic potentials were evoked (2-5 $\mathrm{mV}$ in amplitude, 50 were averaged) after rhythmic oscillations had been blocked by a solution containing $11.5 \mathrm{~mm} \mathrm{MgCl}_{2}$ and $1 \mu \mathrm{M}$ TTX. The membrane potential was held between -70 and $-80 \mathrm{mV}$. In 7 of 9 neurons from neonatal rats, the electrotonic potential was better fit by the sum of 2 exponential functions than by 1 ; with a rectangular current pulse of $50 \mathrm{pA}$, the potential change had components of amplitudes $\left(A_{1}\right) 2.4 \pm 0.9$ and $\left(A_{2}\right) 0.93 \pm 0.26$ $\mathrm{mV}$, having time constants of $\left(\tau_{1}\right) 31.4 \pm 2.0$ and $\left(\tau_{2}\right)$ and 7.9 $\pm 1.5 \mathrm{msec}$. The apparent input resistance for this group was $67 \mathrm{M} \Omega$.

Seven neurons from adult rats were also analyzed in detail; in 3 of 7 the electrotonic potential was significantly better fit by 2 than by 1 exponential function, but the actual values varied greatly from cell to cell and were not easily interpretable $\left(A_{1}\right.$ $2.8,3.2$, and $3.4 \mathrm{mV} ; \mathrm{A}_{2} 0.54,0.11$, and $0.68 \mathrm{mV} ; \tau_{1} 115,53$, and $139 \mathrm{msec} ; \tau_{2} 34.5,2.4$, and $64 \mathrm{msec}$ ). The 4 adult cells that were better fit by a single exponential had a time constant of $55.6 \pm 3.1 \mathrm{msec}$. The input resistance of all 7 adult cells was $213 \perp 33 \mathrm{M} \Omega$, which is not different from the value $(201 \pm 21$ $\mathrm{M} \Omega, n=19$ ) found in an earlier study (Williams et al., 1984). 


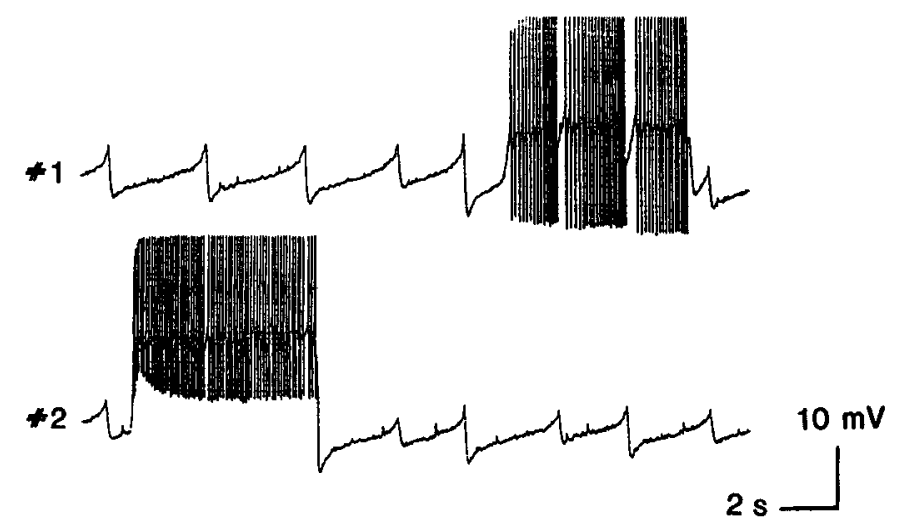

Figure 5. Simultaneous recordings from LC neurons taken from a 5-d-old rat (electrode separation about $80 \mu \mathrm{m}$ ). Spontaneous action potentials were prevented by passing current through the recording electrodes. The bursts of action potentials were evoked by reversing this to a depolarizing current $(300 \mathrm{pA}, 5 \mathrm{sec})$, first in cell 2 and then in cell 1. Although rhythmic potentials were fully synchronous, the bursts of action potentials were not detectable in the other neuron.

\section{Electrotonic coupling between pairs of cells}

Spontaneous or evoked action potentials in one cell did not result in detectable changes in the membrane potential of the second cell. Figure 5 shows an example of an experiment in which current injection was used to evoke action potentials at high frequency in one cell. There was no evidence of a sustained depolarization or electrotonically coupled action potentials in the second cell. Similar results were observed in 22 paired impalements that were separated by $50-200 \mu \mathrm{m}$. When rhythmic oscillations were abolished by TTX (600 nM), TEA (20 mM), and $\mathrm{MgCl}_{2}(11.5 \mathrm{~mm})$, the current injected into one cell caused a detectable potential change in the other cell in 12 out of 29 pairs from rats $<10$ d old (Fig. 6) but not in 4 of 4 pairs from older rats. Hyperpolarizing and depolarizing current pulses $100-$
$300 \mathrm{msec}$ in duration and 1-2 $\mathrm{nA}$ in amplitude were passed into one cell (sending cell) to evoke an electrotonic potential of 70$100 \mathrm{mV}$ in amplitude. The membrane potential was recorded in the other cell (receiving cell) (Fig. 6). In cells that showed coupling, a $100 \mathrm{mV}$ electrotonic potential in the sending cell evoked a $1.2 \pm 0.1 \mathrm{mV}(n=12)$ electrotonic potential in the receiving cell, i.e., the mean coupling ratio was 0.012 . We did not make a quantitative analysis of the electrotonic potentials in coupled cells because (1) we did not know the precise separation of the electrode tips within the slice, and (2) it was difficult in most cells to pass the very large currents for a period of time sufficiently long to charge fully the capacitance of the receiving cell(s). No coupled potentials were observed when the electrode tip was removed from the receiving cell to an immediately extracellular position $(n=18)$.

\section{Discussion}

Previous work showed that subthreshold rhythmic oscillations in the membrane potential of LC neurons from neonates are dependent on extracellular calcium, are unrelated to the fast sodium-dependent action potentials, and are unaffected by changes in membrane potential resulting from current passed through the recording electrode (Williams and Marshall, 1987). The present study demonstrates, first, that these oscillations in membrane potential are highly synchronized throughout the nucleus. Second, we have demonstrated direct electrical coupling between these neurons. These low-resistance junctions could contribute significantly to the overall membrane properties of the neonatal LC neurons and, thus, to the physiological behavior of the entire nucleus.

Analysis of electrotonic potentials indicated that the majority of neonatal neurons present 2 distinct electrical compartments. There are 2 possible interpretations of these results. The cells may have extensive dendrites, or they may be electrically coupled; the fast component would then result from the charging of the dendritic tree or from the spread of current along the
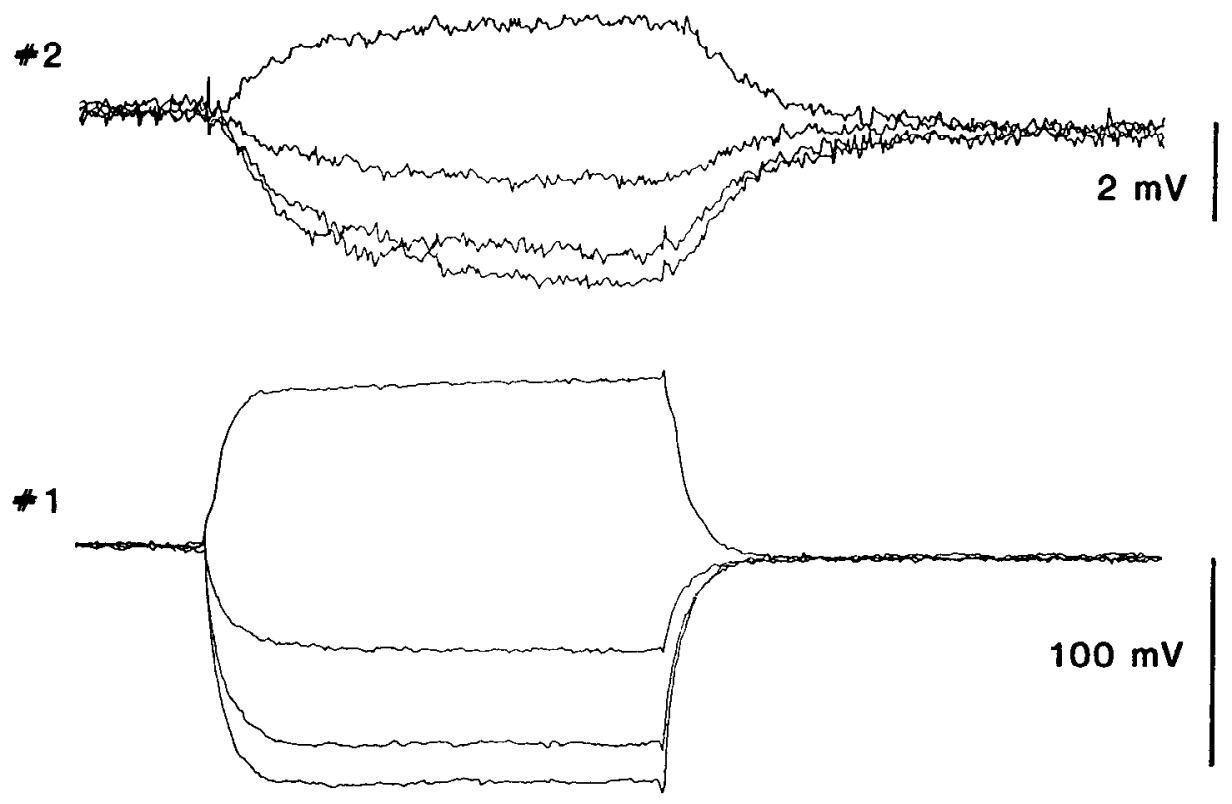

Figure 6. Electrotonic coupling between LC neurons. Simultaneous recordings from 2 cells from a 9-d-old rat (electrode separation about $80 \mu \mathrm{m}$ ). Traces show electrotonic potentials at each electrode (average of 10 ) evoked by current pulses (1-2 $\mathrm{nA}, 200 \mathrm{msec})$ passed through electrode 1 . The amplitude of the electrotonic potential recorded in neuron 2 was about $2 \%$ of that recorded in neuron 1 . Solution contained tetraethylammonium (20 $\mathrm{mM}$ ), magnesium (5 mM), barium (200 $\mu \mathrm{M})$, and TTX (300 nM). 
distributed capacitance and resistance of adjoining coupled cells. Although we cannot rule out a contribution from the former, we have directly demonstrated the latter. Analysis of the values for amplitude and time constant of the 2 compartments using the method of Publicover (1984), which assumes a large network of identical cells coupled by low-resistance pathways, indicates that each neuron should be connected on average with 1.9 other cells.

The direct evidence for coupling among the neurons came from the experiments in which current injected into one cell caused a potential change in a second cell. The coupling ratio was small, ranging from $0.005-0.02$; this might result from the difficulty in obtaining impalement of pairs of cells very close to each other. The failure to detect coupling in $59 \%$ of pairs could result from the potential change in the receiving neuron being less than $0.5 \mathrm{mV}$, the usual limit of detection. The small amplitude of the electrotonic potential in the receiving cell precluded quantitative analysis of its onset and time course, although the apparent time constant of the potential change in the receiving cell was substantially longer than the time constant of the sending cell (Fig. 6). These findings are consistent with a long electrotonic length between the pairs of neurons sampled.

Taken together, we interpret these results as evidence that neurons in the neonatal LC are coupled to each other by lowresistance electrical pathways. The overall properties of the network are equivalent to each cell being coupled to an average of 2 others, and results in a spread through the entire nucleus of any potential changes occurring more slowly than about 1 $\mathrm{V} / \mathrm{sec}$. Thus, electrical coupling has the properties of a low-pass filter, synchronizing slow spontaneous oscillations, but not full action potentials.

The most likely basis for electrotonic coupling is direct cellcell coupling via gap junctions. Electron microscopic studies did not detect gap junctions between adult LC neurons (e.g., Groves and Wilson, 1980), but we are unaware of any such studies in neonates. Sectioning of the dendritic field has been proposed to produce artifactual coupling in slice preparations of guinea pig cortex (Gutnick et al., 1985). However, we found no influence of the plane of section on the synchrony of neonatal LC neurons. We also found no coupling between cells of the left and right locus coeruleus. Another possible explanation for the synchronous activity might be synchrony of excitatory synaptic input throughout the nucleus; neonatal LC neurons in vivo clearly receive afferent input (Sakaguchi and Nakamura, 1987). This seems unlikely for 2 reasons. The first is that the sources of afferent input to the LC have been removed when the slice is prepared (Aston-Jones et al., 1986), and the second is that TTX would be expected to block activity in the afferent fibers (see Williams et al., 1984).

Both synchronous rhythmic activity and electrotonic coupling declined with the age of the animals. It was possible to detect electrotonic coupling in pairs of cells only in animals less than $10 \mathrm{~d}$ old. In addition, the rhythmic oscillations were found only occasionally after $25 \mathrm{~d}$ (Williams ct al., 1984), and no spontaneous synchronized activity was observed between 60 pairs of adult LC neurons (Y. Katayama and J. T. Williams, unpublished observations). These findings suggest that the low-resistance coupling necessary for entrainment of rhythmic activity becomes less significant with age.

The synchronous calcium-dependent rhythmic oscillations found in the present investigation are similar to those described in inferior olivary neurons of the guinea pig (Llinás and Yarom, 1981a, b, 1985; Benardo and Foster, 1986). Although full action potentials could occur independently, the oscillations generally resulted in the entrainment of activity at the peaks of the slow depolarizations. Such synchronous activity of olivary neurons may play a role in motor coordination and was suggested to be the basis for the physiological tremor which occurs in man (Llinás and Yarom, 1985).

We found that full action potcntials often were activated at the peaks of the slow depolarizations, indicating that the oscillations in membrane potential could result in the nearly simultaneous discharge of many LC neurons. Recordings in vivo from fetal (E18-E22) and neonatal (P1-P3) rats also indicated that the LC neurons fired synchronous spontaneous action potentials in "sporadic epochs" (Kimura and Nakamura, 1985; Sakaguchi and Nakamura, 1987). It was also noted that the amplitude of the field response evoked by electrical stimulation of the dorsal noradrenergic bundle or frontal cortex varied with time. The amplitude of this field potential is dependent on the number of LC neurons activated, and this number could vary substantially depending on the timing of the stimulus with the phase of the slow depolarizations.

Two possible functional roles for rhythmic oscillations in $\mathrm{LC}$ neurons during early postnatal development follow. Considering that synaptogenesis is not complete, the coupling bctween cells early in development would increase the number of cells responding to afferent input: indeed, LC cells in fetal rats were found to respond vigorously to sensory stimulation of the skin (Sakagushi and Nakamura, 1987). Second, noradrenaline has been proposed to play a role in developmental plasticity; the synchronous pattern of discharge of LC neurons implies that the diverse innervated areas of the neuraxis (Lauder and Bloum, 1974) receive the same oscillatory influence of released noradrenaline.

\section{References}

Aston-Jones, G., M. Ennis, V. A. Pieribone, W. T. Nickell, and M. T. Shipley (1986) The brain nucleus locus coeruleus: Restricted afferent control of a broad efferent network. Science 234: 734-737.

Benardo, L. S., and R. E. Foster (1986) Oscillatory behavior in inferior olive neurons: Mechanism, modulation, cell aggregates. Brain Res. 17: 773-784.

Christie, M. J., J. T. Williams, and R. A. North (1987) Synchronous activity in locus coeruleus neurons from neonatal rats. Soc. Neurosci. Abstr. 13: 538

Connors, B. W., L. S. Benardo, and D. A. Prince (1983) Coupling between neurons of the developing rat neocortex. J. Neurosci. 3:773782.

Coyle, J. T., and M. E. Molliver (1977) Major innervation of newborn rat cortex by monoaminergic neurons. Science 196: 444-447.

Felten, D. L., H. Hakan, and G. Jonsson (1982) Evidence for a neurotrophic role of noradrenaline neurons in the postnatal development of rat cerebral cortex. J. Neurocytol. 11: 119-135.

Foote, S. L., F. E. Bloom, and G. Aston-Jones (1983) Nucleus locus coeruleus: New evidence of anatomical and physiological specificity. Physiol. Rev. 63: 844-914.

Groves, P. M., and C. H. Wilson (1980) Fine structure of rat locus coeruleus. J. Comp. Neurol. 193: 841-852.

Gutnick, M. J., R. Lobel-Yaakov, and G. Rimon (1985) Incidence of neuronal dye-coupling in neocortical slices depends on the plane of section. Neuroscience 15: 659-666.

Kimura, F., and S. Nakamura (1985) Locus coeruleus neurons in the neonatal rat: Electrical activity and responses to sensory stimulation. Dev. Brain Res. 23: 301-305.

Lauder, J. M., and F. E. Bloom (1974) Ontogeny of monoamine neurons in the locus coeruleus, raphe nuclei and substantia nigra of the rat. I. Cell differentiation. J. Comp. Neurol. 155: 469-482.

Lauder, J. M., and F. E. Bloom (1975) Ontogeny of monoamine neu- 
rons in the locus coeruleus, raphe nuclei and substantia nigra of the rat. II. Synaptogenesis. J. Comp. Neurol. 163: 251-264.

Llinás, R., and Y. Yarom (1981a) Electrophysiology of mammalian inferior olivary neurons in vitro. Different types of voltage-dependent ionic conductances. J. Physiol. (Lond.) 315: 549-567.

Llinás, R., and Y. Yarom (1981b) Properties and distribution of ionic conductances generating electroresponsiveness of mammalian inferior olivary neurons in vitro. J. Physiol. (Lond.) 315: 569-584.

Llinás, R., and Y. Yarom (1985) Oscillatory properties of guinea-pig inferior olivary neurones and their pharmacological modulation: an in vitro study. J. Physiol. (Lond.) 376: 163-182.

Publicover, N. G. (1984) Single microclectrode analysis of clectrically coupled networks. IEEE Trans. Biomed. Engin. 32: 491-496.
Sakaguchi, T., and S. Nakamura (1987) Some in vivo electrophysiological properties of locus coeruleus neurones in fetal rats. Exp. Brain Res. 68: 122-130.

Specht, L. A., V. M. Pickel, T. H. Joh, and D. J. Reis (1981) Lightmicroscopic immunocytochemical localization of tyrosine hydroxylase in prenatal rat brain. I. Early ontogeny. J. Comp. Neurol. 199: 233-253.

Williams, J. T., and K. C. Marshall (1987) Membrane properties and adrenergic responses in locus coeruleus neurons of young rats. J. Neurosci. 7: 3687-3694.

Williams, J. T., R. A. North, A. Shefner, S. Nishi, and T. M. Egan (1984) Membranc properties of rat locus coeruleus neurones. Neuroscience 13: 137-156. 